\title{
Dente hipoplásico de Turner: relato de casos clínicos
}

\author{
Turner's Hypoplasia Tooth: Clinical Case Reports
}

\author{
Priscila Hernández de Campos* \\ Vania D'Angelo Rodrigues Antunes dos Santos ${ }^{* *}$ \\ Renata de Oliveira Guaré*** \\ Michele Baffi Diniz ${ }^{* * *}$
}

\section{Resumo}

Objetivo: demonstrar as características do dente hipoplásico de Turner e suas possíveis causas por meio de relato de casos, ressaltando a importância da sua detecção precoce e o diagnóstico diferencial com outros defeitos de desenvolvimento do esmalte dentário. $O$ dente de Turner é uma hipoplasia de esmalte localizada, caracterizada por um defeito na qualidade e na espessura do esmalte. Os dentes mais acometidos são os pré-molares superiores e inferiores. A etiologia mais provável é decorrente de uma infecção periapical que estava presente no dente decíduo predecessor, afetando o desenvolvimento do dente permanente. A severidade da hipoplasia pode variar desde manchas esbranquiçadas e de coloração pardo-acastanhada até a perda de estrutura dentária, que influenciará na conduta clínica apropriada, além do grau de sensibilidade dentinária, comportamento do paciente e risco de cárie. Relato de caso: apresentar dois casos clínicos de pacientes infantis com dente hipoplásico de Tunner em pré-molar, com diferentes graus de severidade e condutas clínicas. Considerações finais: o conhecimento dos aspectos patognomônicos do dente hipoplásico de Turner é fundamental para um correto diagnóstico e a elaboração de um plano de tratamento adequado, visando preservar a estrutura dentária, facilitar a higiene bucal e diminuir a sensibilidade.

Palavras-chave: Hipoplasia do Esmalte Dentário. Cárie Dentária. Dente Pré-Molar. Criança.

\section{Introdução}

A hipoplasia de esmalte é definida como um defeito quantitativo da estrutura externa do dente, associada à redução da espessura do esmalte. As lesões hipoplásicas são formadas na fase secretória da amelogênese, tendo a sua severidade definida pela duração e a intensidade da agressão sofrida ${ }^{1-5}$.

Essas podem afetar tanto a dentição decídua como a permanente e, com isso, comprometer vários elementos ou apenas um, apresentando como causa fatores sistêmicos, locais ou hereditários ${ }^{6}$. A etiologia da hipoplasia localizada pode envolver fatores traumáticos ou disseminação de uma infecção periapical ${ }^{7}$.

Turner $^{8}$ (1912) foi o primeiro a observar a hipoplasia localizada em dentes permanentes inferiores, relacionando-a a um processo inflamatório severo nos decíduos predecessores, tendo ficado conhecida como hipoplasia de Turner ou dente de Turner. ${ }^{6}$ Quando ocorre infecção, devido à presença de cárie no dente decíduo e o sucessor permanente está em formação, a infecção bacteriana pode envolver o tecido periapical do dente decíduo, podendo alterar a camada ameloblástica do permanente, resultando numa coroa hipoplásica ${ }^{9}$.

Os elementos dentários mais acometidos são os incisivos permanentes superiores e os pré-molares superiores e inferiores ${ }^{10}$. Clinicamente, os dentes de Turner apresentam dimensão reduzida, com o defei-

\footnotetext{
Especialista e Mestre em Odontopediatria e Doutoranda em Odontopediatria da Universidade Cruzeiro do Sul - Unicsul, São Paulo-SP, Brasil.

Especialista em Ortodontia e Mestranda em Odontopediatria da Universidade Cruzeiro do Sul - Unicsul, São Paulo-SP, Brasil.

* Professora Doutora da Disciplina de Odontopediatria da Universidade Cruzeiro do Sul - Unicsul, São Paulo-SP, Brasil.
} 
to de esmalte variando de ranhuras imperceptíveis, manchas esbranquiçadas até uma coloração amarelo-pardo com irregularidades na coroa do dente, podendo causar sensibilidade dentinária ${ }^{10,11-12}$. $\mathrm{O}$ tratamento dessas alterações dependerá da severidade da hipoplasia que o dente apresenta ${ }^{6,10,13-15}$.

Assim, o objetivo foi apresentar o relato de dois casos clínicos de pacientes infantis com dente hipoplásicos de Turner em pré-molares e sua conduta clínica, ressaltando a importância da sua detecção precoce e o diagnóstico diferencial com outros defeitos de desenvolvimento do esmalte dentário.

\section{Relatos de casos clínicos}

O responsável pelas crianças assinou o Termo de Consentimento Livre e Esclarecido autorizando a documentação e a publicação dos casos.

\section{Caso clínico 1}

Paciente do sexo feminino, 10 anos de idade, de origem hispânica, compareceu à Clínica Infantil da Universidade Cruzeiro do Sul, com sensibilidade dentária em um dente inferior. Durante a anamnese foi relatado um quadro de cárie precoce da infância na dentadura decídua e a necessidade de exodontia do elemento 85, por uma infecção crônica. A criança apresentava comportamento não colaborador.

No exame clínico, observou-se a presença de hipoplasia de esmalte, envolvendo toda a coroa do dente 45, com coloração acastanhada e irregular, perda de estrutura dentária e com dimensão reduzida (Figura 1). No exame radiográfico, notou-se que o dente apresentava formação estrutural inadequada de coroa e raiz (Figura 2 ). Frente ao relato na anamnese e às características clínicas e radiográficas, o diagnóstico para a hipoplasia foi dente de Turner.

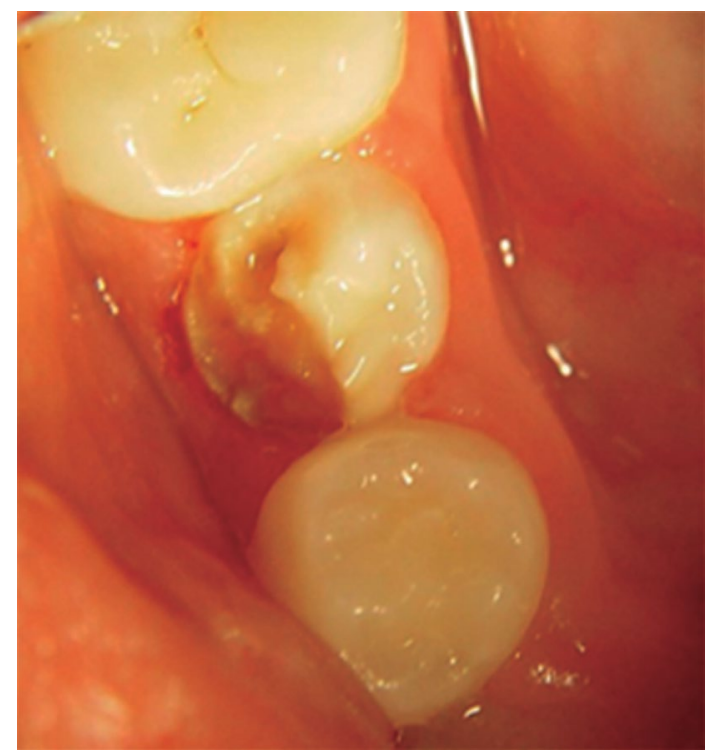

Figura 1 - Aspecto clínico do dente 45 com hipoplasia de Turner. Observa-se a coloração acastanhada e irregular, com perda de estrutura e dimensão reduzida da coroa dentária

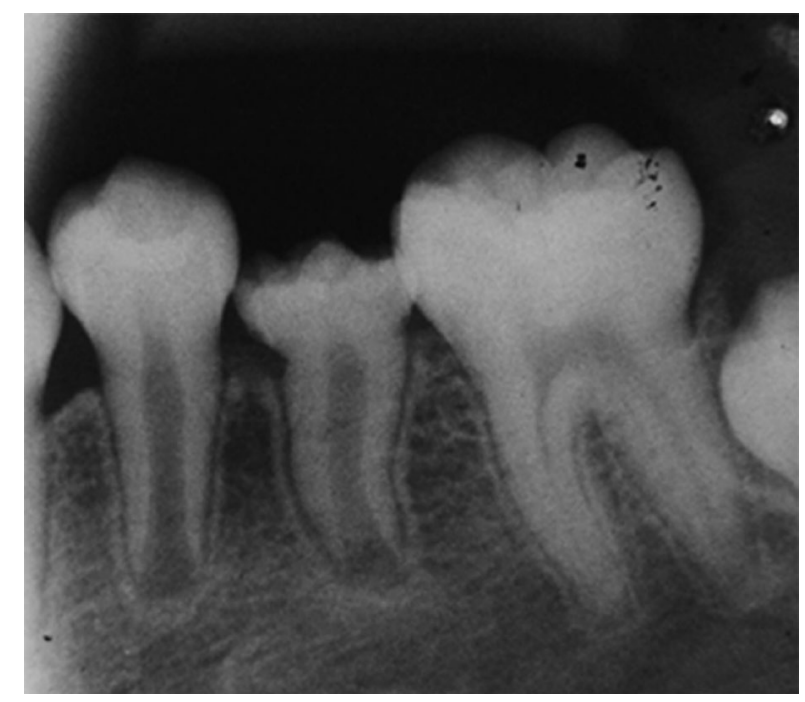

Figura 2 - Radiografia periapical do dente 45. Verifica-se a formação estrutural inadequada de coroa e raiz.

Como o elemento 45 apresentava acentuada redução de tamanho de sua coroa e com sensibilidade e a criança era não colaboradora, o tratamento proposto foi a restauração da superfície com cimento de ionômero de vidro (Ketac Molar EasyMix, 3M ESPE, St. Paul, MN, EUA) com o objetivo de preservar estrutura dentária, facilitar a higiene bucal e diminuir a sensibilidade.

Inicialmente, foi realizada a profilaxia com pedra pomes e escova de Robson para eliminar resíduos sobre a superfície do elemento dentário. Em seguida, sob isolamento relativo, foi aplicado o ácido poliacrílico (Ketac Conditioner, 3M ESPE, St. Paul, MN, EUA) com um microbrush por 20 segundos. Após lavagem e secagem, aplicou-se cimento de ionômero de vidro seguido da pressão digital e da proteção da superfície com verniz (Ketac Glaze, 3M ESPE, St. Paul, MN, EUA) (Figura 3).

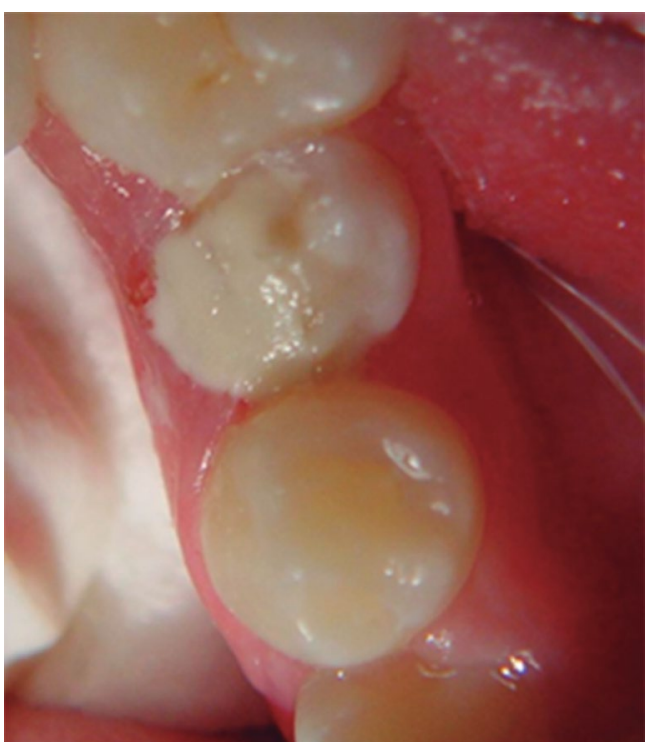

Figura 3 - Apecto clínico do dente 45 após aplicação do cimento de ionômero de vidro 
A paciente está em acompanhamento na clínica odontológica até que seu manejo comportamental e idade permitam a realização de um tratamento definitivo, como uma restauração adesiva ou coroa total.

\section{Caso clínico 2}

Paciente do sexo feminino, 11 anos de idade, de cor parda, compareceu à Clínica Infantil da Universidade Cruzeiro do Sul - SP para consulta odontológica. A paciente apresentava boa saúde geral e foi relatado histórico de lesões de cárie extensas em molares decíduos, com perda precoce.

Ao exame clínico observou-se que a paciente apresentava baixo risco de cárie. Notou-se a presença de hipoplasia de esmalte, envolvendo o dente 25 , com coloração acastanhada e irregular nas superfícies vestibular e palatina e em infra-oclusão (Figura 4). Ao exame radiográfico notou-se que o dente apresentava formação radicular incompleta (estágio 8 de Nolla) e redução da dimensão coronária (Figura 5). O diagnóstico para a hipoplasia foi dente de Turner, devido às características clínicas, radiográficas e do relato da anamnese.

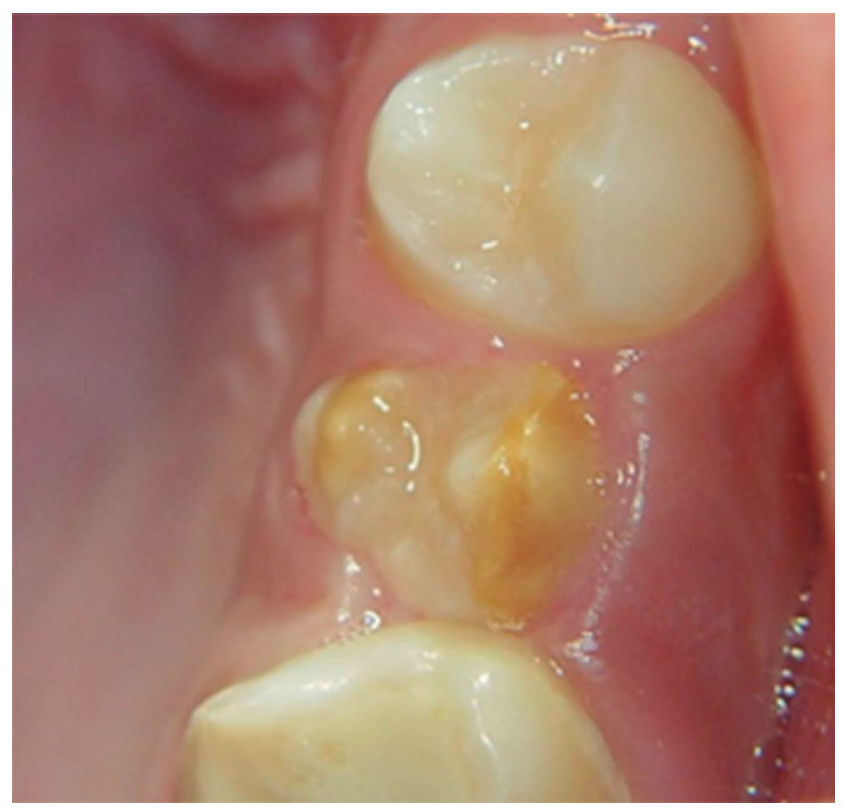

Figura 4 - Aspecto clínico do dente 25 com hipoplasia de Turner. Verifica-se $o$ aspecto de infra-oclusão e a coloração acastanhada e irregular nas superfícies vestibular e palatina

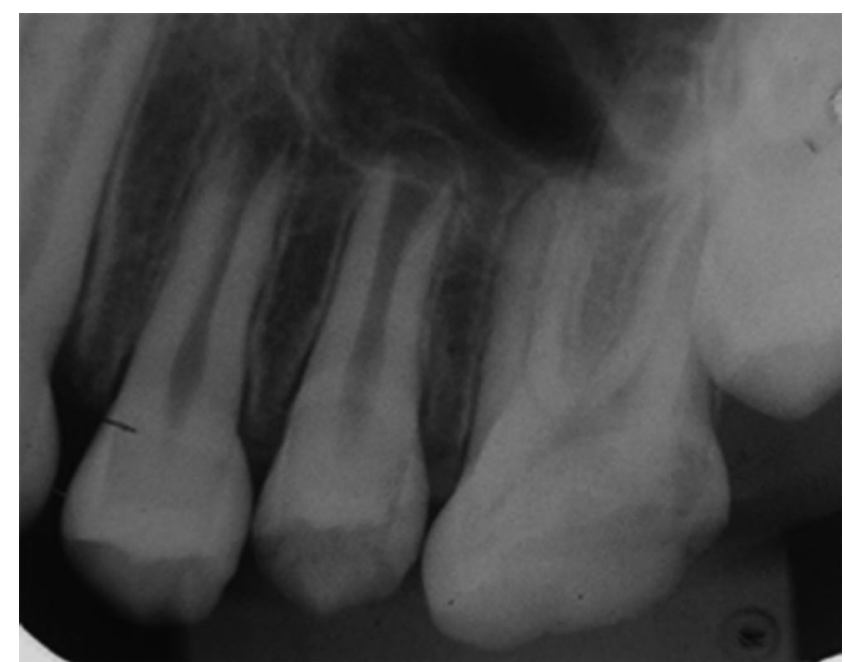

Figura 5 - Radiografia periapical do dente 25. Observa-se a redução da dimensão coronária e formação radicular incompleta

Como o elemento 25 estava em infra-oclusão, optou-se em fazer aplicação tópica de verniz fluoretado (Lase Sensy II, NaF 5\%, DMC, São Carlos, SP, Brasil) com o objetivo de controlar a sensibilidade. Inicialmente, foi realizada a profilaxia com pedra pomes e escova de Robson e, em seguida, sob isolamento relativo, foi aplicado o verniz com microbrush (Figura 6). Esse procedimento está sendo realizado mensalmente.

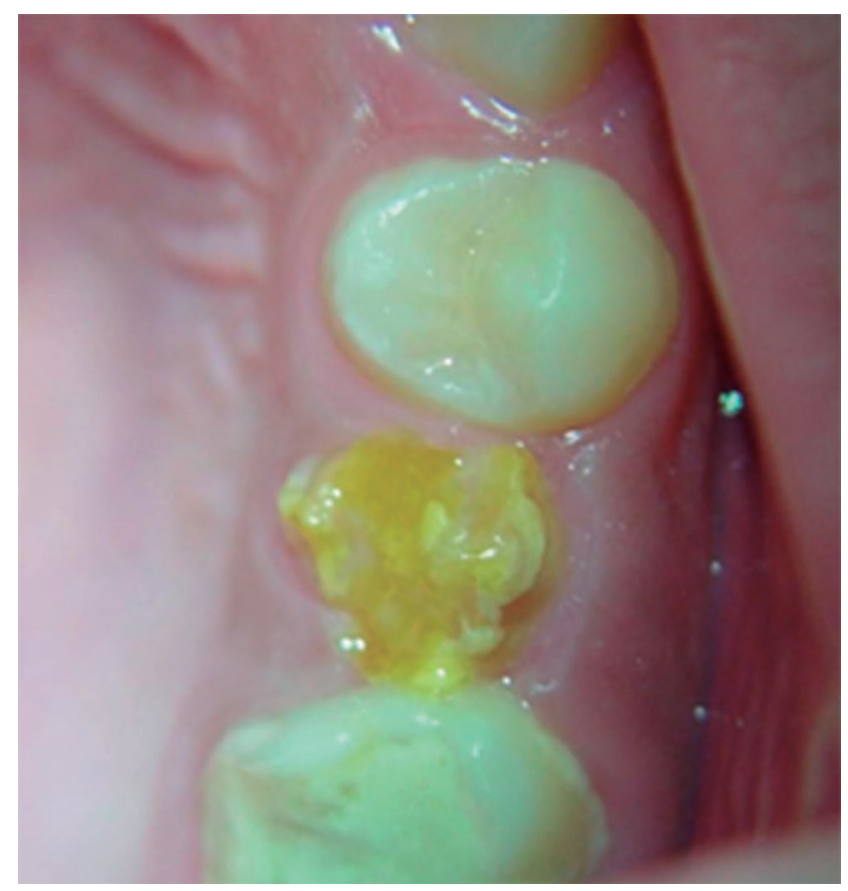

Figura 6 - Aspecto clínico do dente 25, após a aplicação do verniz fluoretado

A paciente está sob acompanhamento para verificar a formação radicular completa e avaliação de um procedimento restaurador estético definitivo. 


\section{Discussão}

O diagnóstico de hipoplasia de esmalte muitas vezes pode ser complicado, podendo ser confundindo com muitas outras alterações do esmalte como hipomineralização, hipomaturação e hipocalcificação. A hipomineralização corresponde a um distúrbio da fase de maturação do esmalte, sendo um defeito qualitativo, podendo apresentar uma área branca, castanha, creme ou amarelada com limite evidente em relação ao esmalte normal adjacente ${ }^{16}$. Na hipomaturação, os cristais de esmalte permanecem imaturos, sendo um defeito no crescimento e na orientação dos cristais de hidroxiapatita, com radiodensidade igual à dentina ${ }^{9,17}$. A hipocalcificação ocorre quando há ausência na mineralização do esmalte, apresentando rugosidade e friabilidade que leva à fratura. Geralmente, os pacientes que apresentam hipocalcificação apresentam muita sensibilidade ao higienizar os dentes, acarretando o desenvolvimento de gengivite e periodontite crônica ${ }^{17}$.

A hipoplasia é uma alteração que ocorre quando há uma agressão aos ameloblastos na fase de formação da matriz do esmalte, resultando na redução de sua espessura. ${ }^{1,18}$ Sua severidade e duração determina a extensão da lesão hipoplásica ${ }^{10}$. Clinicamente, visualizar desde pequenas ranhuras e manchas até a ausência parcial ou completa do esmalte, podendo, com isso, acarretar sensibilidade ${ }^{10,11,12}$. Nos casos apresentados, pode-se observar a variação da hipoplasia com manchas acastanhadas até a perda parcial da estrutura dentária.

A hipoplasia do esmalte pode apresentar etiologias diversas, dentre elas a de caráter local por infecção, chamada de dente de Turner. $\mathrm{O}$ dente de Turner ocorre quando um dente decíduo cariado apresenta uma infecção bacteriana que atinge o tecido periapical, afetando o dente permanente sucessor que ainda está em fase de formação da coroa $^{8-10}$. A severidade dessa hipoplasia dependerá da gravidade da infecção e da fase de formação do permanente ${ }^{9}$. Esse tipo de hipoplasia é mais prevalente em pré-molares superiores ou inferiores, como observado nos casos clínicos apresentados em que houve um histórico de infecção nos molares decíduos predecessores ${ }^{9,10,12}$.

Clinicamente, esse tipo de alteração pode variar desde manchas esbranquiçadas e ranhuras com coloração amarelo-pardo até irregularidades na coroa com redução de suas dimensões ${ }^{10,11,12}$ como observado nos casos apresentados. Além disso, os elementos dentais apresentavam dimensões reduzidas e no primeiro caso, com perda considerável de esmalte na coroa do dente, causando maior sensibilidade ao paciente. No primeiro, observou-se radiograficamente formação estrutural inadequada de coroa e raiz, sinais encontrados com frequência nesse tipo de hipoplasia ${ }^{10}$. Vale ressaltar que, no segundo caso, o dente apresenta-se em infra-oclusão e formação radicular com estágio 8 de Nolla.

O tratamento da hipoplasia de esmalte varia de acordo com a severidade da alteração e também com a idade e o comportamento da criança, podendo ser indicadas desde aplicações tópicas de flúor ${ }^{6,19}$ até procedimentos restauradores, reabilitadores e estéticos ${ }^{3,5,6,13-15,20}$. No primeiro caso apresentado, optou-se pela utilização do cimento de ionômero de vidro, justificado pela grande sensibilidade que 0 dente apresentava, alta atividade de doença cárie e pelo comportamento não colaborador, conforme preconizado na literatura ${ }^{10,14}$. No segundo caso, por se tratar de uma paciente de baixo risco de cárie e com sensibilidade no elemento 25 , sem perda de estrutura de esmalte, empregou-se o verniz fluoretado para vedamento dos túbulos dentinários ${ }^{6,19}$.

\section{Conclusão}

É importante o conhecimento dos fatores etiológicos, clínicos e radiográficos para um correto diagnóstico e elaboração de um plano de tratamento adequado do dente hipoplásico de Turner, levando em consideração a severidade da alteração, o grau de sensibilidade dentinária, o comportamento do paciente e o risco de cárie.

\section{Abstract}

Objective: to show the characteristics of Turner's hypoplasia and its potential causes through case reports, emphasizing the importance of early detection and differential diagnosis with other development defects of tooth enamel. Turner's tooth is a local enamel hypoplasia, featured by a defect in quality and thickness of enamel. The most affected teeth are upper and lower premolars. The most likely etiology is from a periapical infection that was present in the primary tooth predecessor, affecting the development of the permanent tooth. The severity of hypoplasia may range from whitish or brownish stains to loss of tooth structure, which will influence proper clinical management, in addition to the degree of dentinal sensitivity, patient behavior, and caries risk. Case Reports: to present two case reports of pediatric patients with Turner's hypoplasia in premolars, with different degrees of severity and clinical procedures. Final considerations: the knowledge of the pathognomonic aspects of Turner's hypoplasia is essential for correct diagnosis and determination of an appropriate treatment plan, aiming to preserve tooth structure, facilitate oral hygiene, and decrease tooth sensitivity.

Keywords: Dental Enamel Hypoplasia. Dental Caries. Premolar Tooth. Child. 


\section{Referências}

1. Li Y, Navia JM, Bian JY. Caries experience in deciduous dentition of rural Chinese children 3-5 years old in relation to the presence or absence of enamel hypoplasia. Caries Res 1996;30(1):8-15.

2. Medina AAJ, Moro NRNL. Amelogênese imperfeita: relato de caso clínico. J Bras Ortodon Ortop Facial 2001;6(31):21-4.

3. Oliveira AFB, Rosenblatt A. Defeitos do esmalte: o que o odontopediatra precisa saber. Rev ABO Nac 2002;10(5):274-7.

4. Marsillac MWS, Batista AMR, Oliveira J, Rocha MJC. Alterações na amelogênese e suas implicações clínicas: relatos de casos. Rev Fac Odontol, Porto Alegre 2009;50(1):9-15.

5. Singh AP, Malhan S, Monga P, Bajaj N, Kaur H. Esthetic management of Turner's hypoplasia. Ind J Dent Sci 2012;4(4):73-4.

6. Ribas AO, Czlusniak GD. Anomalias do esmalte dental: etiologia, diagnóstico e tratamento. Publ UEPG Ci Biol Saúde 2004;10(1):23-36.

7. Passos IA, Costa JDMC, Melo JM, Forte FDS, Sampaio FC. Defeitos do esmalte: etiologia, características clínicas e diagnóstico diferencial. Rev Inst Ciênc Saúde 2007;25(2):187-92.

8. Turner JG. Two cases of hypoplasia of enamel. Proc R Soc Med 1912;5(Odontol Sect):73-6.

9. Shafer WG, Hine MK, Levy BM. Distúrbios do desenvolvimento das estruturas bucais e parabucais. In: Shafer WG, Hine MK, Levy BM. Tratado de patologia bucal. 4. ed. Rio de Janeiro: Guanabara Koogan; 1987. p. 02-79.

10. Braga LCC, Mazetto AH, Grigoletto M, Paganini GA, Vedovello SAS, Chagas Jr CL. Hipoplasia de esmalte localizada - Dente de Turner. RGO 2005;53(4):329-34.

11. Gonçalves AF, Ferreira SLM. Defeitos hipoplásicos do esmalte dentário: revisão de literatura. Rev Odontol Univ St Amaro 2000;5(1):13-20.

12. Hass NAT, Vasconcelos MFC, Cario RD, Santos MAV, Alves MU, Silveira JLGC. Dente de Turner. Rev Paul Odontol 2003;25(2):8-10

13. Marangoni MH, Carvalho RM. Dentística cosmética em hipoplasias de esmalte. RGO 1992;40(5):344-5.

14. Li RW. Adhesive solutions: report of a case using multiple adhesive techniques in the management of enamel hypoplasia. Dent Update 1999;26(7):277-82, 284, 287-7.

15. Kabbach W. Abordagem conservadora para o tratamento de hipoplasia do esmalte. Clín Int J Braz Dent 2010;6(2):13041.

16. Sabel N. Enamel of primary teeth--morphological and chemical aspects. Swed Dent J Suppl 2012;(222):1-77.

17. Hu JC, Chun YH, Al Hazzazzi T, Simmer JP. Enamel formation and amelogenesis imperfecta. Cells Tissues Organs 2007;186(1):78-85.

18. Chagas MS, Jácomo DRES, Campos UR. Frequência da hipoplasia do esmalte nos dentes permanentes anteriores decorrente de traumatismo nos antecessores. Arq Bras Odontol 2007;3(1):73-83.

19. Geetha Priya PR, John JB, Elango I. Turner's hypoplasia and non-vitality: a case report of sequelae in permanent tooth. Contemp Clin Dent 2010;1(4):251-4.

20. Brushan BA, Garg S, Sharma D, Jain M. Esthetic and endosurgical management of turner's hypoplasia; a sequlae of trauma to developing tooth germ. J Indian Soc Pedod Prevent Dent 2008;26(Suppl 3):S121-4.

\section{Endereço para correspondência:}

Profa. Dra. Michele Baffi Diniz

Universidade Cruzeiro do Sul - Setor de Pós Graduação Rua: Galvão Bueno, 868 Liberdade

01506-000 São Paulo - SP

Telefone: (11) 3385-3015

E-mail:mibdiniz@hotmail.com

Recebido: 26/02/2015. Aceito: 26/03/2015. 